\title{
CALAGEM EM LATOSSOLO SOB INFLUÊNCIA DE COBERTURAS VEGETAIS: NEUTRALIZAÇÃO DA ACIDEZ ${ }^{(1)}$
}

\author{
Tullio Raphael Pereira de Pádua ${ }^{(2)}$, Carlos Alberto Silva ${ }^{(3)} \&$ Leônidas \\ Carrijo Azevedo Melo ${ }^{(4)}$
}

\begin{abstract}
RESUMO
A movimentação dos produtos da dissolução do calcário e a correção da acidez podem ser influenciadas pelo manejo da calagem e pela quantidade e qualidade da matéria orgânica presente no solo. Avaliou-se a correção da acidez de acordo com a aplicação de calcário superficial ou incorporado nas profundidades de 0-10, 0-20 cm, em um Latossolo Vermelho distroférrico (LVdf) sob diferentes coberturas vegetais anteriores (mata, eucalipto, pinus e pastagem). $O$ estudo foi realizado de novembro de 2002 a janeiro de 2003 no Departamento de Ciência do Solo da UFLA, sendo avaliados, depois de 30 dias de reação do calcário, e antes do cultivo do algodão, os teores trocáveis de $\mathrm{Ca}^{2+} \mathrm{e} \mathrm{Al}^{3+}$, o $\mathrm{pH}$ e os níveis de saturação por bases (V) em amostras de solo coletadas nas profundidades de 0-5, 5-10, 10-20 e 20$40 \mathrm{~cm}$. A calagem superficial causou, na camada de 0-5 cm, uma elevação do $\mathrm{pH}$ e $\mathrm{V}$ para níveis acima dos considerados adequados para o cultivo do algodoeiro, caracterizando uma calagem excessiva. Foram verificados acréscimos, em relação à área sem calagem, do $\mathrm{pH}, \mathrm{Ca}^{2+}$ e saturação por bases em camadas de solo além das camadas de incorporação do corretivo, principalmente nas amostras de solo com maior teor de matéria orgânica, mas esses efeitos não se estenderam à camada de subsolo $(20-40 \mathrm{~cm})$.
\end{abstract}

Termos de indexação: mobilidade de bases, calagem superficial, Gossypium hirsutum L., matéria orgânica.

\footnotetext{
(1) Parte da Dissertação de Mestrado do primeiro autor. Recebido para publicação em maio de 2005 e aprovado em setembro de 2006.

${ }^{(2)}$ Doutorando do Curso de Fitotecnia, Universidade Federal de Lavras - UFLA. Caixa Postal 3037, CEP 37200-000 Lavras (MG). E-mail: trpp2000@yahoo.com.br

(3) Professor do Departamento de Ciência do Solo, UFLA. E-mail: csilva@ufla.br

(4) Mestrando do Curso de Solos e Nutrição de Plantas, UFLA. E-mail: leonidasmelobr@yahoo.com.br
} 


\title{
SUMMARY: LIMING INA LATOSOL UNDER INFLUENCE OF COVER CROPS: ACIDITY NEUTRALIZATION
}

\begin{abstract}
Lime mobility and soil acidity correction can be influenced by liming management and the quantity and quality of soil organic matter. Acidity neutralization in function of the lime incoporation and surface liming was evaluated in a red Latosol (Oxisol) under different antecedent vegetation covers (eucalyptus, forest, pasture and pine). The study was carried out from November 2002 to January 2003 at the Soil Science Department of the Lavras Federal University. After 30 days of incubation of soils with lime, the contents of $\mathrm{Ca}^{2+}$ e $\mathrm{Al}^{3+}, \mathrm{pH}$ and base saturation levels were quantified at the 0-5, 5-10, 10-20 and $20-40 \mathrm{~cm}$ sample depths. At the depth of $0-5 \mathrm{~cm}$, surface liming promoted an increase in $\mathrm{pH}$, base saturation and $\mathrm{Ca}^{2+}$ to levels above those considered optimal for cotton growth, thus characterizing overliming. Compared to the area without liming, the levels of $\mathrm{pH}$, $\mathrm{Ca}^{2+}$ and base saturation were higher in layers beneath those of lime incorporation, mainly in the samples with highest organic matter content. No such effects were verified in the subsoil layer $(20-40 \mathrm{~cm})$.
\end{abstract}

Index terms: base mobility, surface liming, Gossypium hirsutum L., organic matter, chemical attributes.

\section{INTRODUÇÃO}

O algodoeiro é uma planta bastante sensível à acidez, sendo a prática da calagem essencial para a obtenção de altas produtividades (Silva et al., 1995). $\mathrm{O}$ rendimento dessa cultura pode ser drasticamente reduzido, caso a correção da acidez do solo não seja feita de modo correto, principalmente nos solos onde a saturação por bases é inferior a 20 \% (Cia et al., 1999).

O método convencional para a aplicação de calcário ao solo garante uma incorporação uniforme do corretivo nas camadas superficiais (Vale et al., 1997). Existem, contudo, áreas onde a calagem é feita em superfície e isso implica maiores riscos de supercalagem, que se caracterizam pela elevação do pH e modificação nos níveis de alguns nutrientes para valores diferentes dos tecnicamente recomendados para o algodoeiro, e, ainda, por uma correção inadequada da acidez nas camadas mais profundas de solo exploradas pelas raízes da cultura.

Nos solos onde há incorporação de calcário, tornase interessante que o corretivo se movimente para as camadas mais profundas, em razão de ser baixa a disponibilidade de $\mathrm{Ca}^{2+}$ e alto o teor de $\mathrm{Al}^{3+}$ no subsolo. A aplicação superficial de corretivos pode contribuir para a correção eficiente da acidez do solo em áreas já instaladas com culturas perenes (Chaves et al., 1984), em pastagens já estabelecidas e em áreas sob sistema plantio direto (SPD) já consolidadas do sul do País, principalmente nos solos com maior acúmulo de matéria orgânica (Pöttker \& Ben, 1998; Caires et al., 1998, 1999 e 2002; Rheinheimer et al., 2000; Moreira et al., 2001; Gatiboni et al., 2003; Pires et al., 2003).

Verfica-se que novas demandas de pesquisa têm surgido nos últimos anos, sendo exemplo a associada à aplicação de calcário em áreas de cerrado sob SPD, onde é mais difícil produzir palha para cobertura do solo, o que restringe o acúmulo de matéria orgânica na superfície e a movimentação do Ca no perfil do solo. Viabilizar a calagem superficial no cerrado constitui uma demanda recorrente por parte dos agricultores, por se tratar da região de maior expansão da cotonicultura.

Para que ocorra a lixiviação de cátions, é necessário que haja no solo íons acompanhantes, como o cloreto, sulfato, nitrato, formiato, bicarbonato, etc., sendo esse um dos motivos que explicam a baixa mobilidade no solo de $\mathrm{Ca}$ aplicado na forma de carbonato, já que o ânion $\mathrm{CO}_{3}{ }^{2-}$ reage com o $\mathrm{H}^{+}$formando $\mathrm{CO}_{2}$, que evolui para a atmosfera (Miyazawa et al., 2000). Além disso, o calcário apresenta baixa solubilidade e os produtos de sua dissolução movimentam pouco no perfil, contudo, o calcário é efetivo na correção da acidez nas camadas do solo onde sua incorporação é feita. Em solos mais ricos em matéria orgânica, com maior aporte de restos culturais e, ou, com adição de estercos e outros resíduos orgânicos, é comum haver movimentação do Ca para camadas do solo além do local onde esse cátion foi aplicado. Esses resultados podem ser explicados, dentre outros fatores, pela formação e maior mobilidade de sais de fulvato de $\mathrm{Ca}$ em solos adubados com esterco de aves (Liu \& Hue, 1995) ou pela reação de fulvato, originado de carvão, com Ca (Noble et al., 1995).

Assim, considerando o papel das moléculas orgânicas (ácidos orgânicos de baixa massa molar, ácido fúlvico, etc) em neutralizar o $\mathrm{Al}$ tóxico e aumentar a mobilidade de $\mathrm{Ca}^{2+}$ e outros cátions no solo, torna-se importante avaliar a magnitude desses processos em solos cujos teores e composição da matéria orgânica variam de acordo com o uso, tipo de resíduo e práticas de manejo (Franchini et al., 2004). 
Este estudo teve por objetivo avaliar o efeito do manejo da calagem sobre a neutralização da acidez e a movimentação de Ca em amostras de Latossolo sob influência de diferentes usos e coberturas vegetais anteriores, visando ao cultivo subseqüente do solo com algodoeiro.

\section{MATERIAL E MÉTODOS}

O experimento foi realizado em casa de vegetação do Departamento de Ciência do Solo da Universidade Federal de Lavras (UFLA), Minas Gerais, em Latossolo Vermelho distroférrico ( $\mathrm{LVdf}$ ), no período de novembro de 2002 a janeiro de 2003. O delineamento utilizado foi o em blocos casualizados, com três repetições. A análise granulométrica das amostras de solo das áreas estudadas é apresentada no quadro 1.

As análises químicas de amostras do solo sob diferentes coberturas vegetais foram realizadas no Laboratório de Fertilidade do Solo do DCS/UFLA, e os resultados relativos a algumas características do solo são apresentados no quadro 2. As amostras de solo foram coletadas no Campus da Universidade Federal de Lavras, em outubro de 2002, nas profundidades de 0-10, 10-20 e 20-40 cm. Na área sob mata, predomina a vegetação do tipo floresta tropical subcaducifólia; na área de pastagem, foi instalada, há cerca de 15 anos, a Brachiaria
Quadro 1. Textura de amostras de três camadas de Latossolo sob diferentes coberturas vegetais anteriores

\begin{tabular}{|c|c|c|c|}
\hline \multirow{2}{*}{ Cobertura vegetal } & \multicolumn{3}{|c|}{ Granulometria } \\
\hline & Areia & Silte & Argila \\
\hline & \multicolumn{3}{|c|}{$\mathrm{g} \mathrm{kg}^{-1}$} \\
\hline & \multicolumn{3}{|c|}{$0-10 \mathrm{~cm}$} \\
\hline Eucalipto & 190 & 90 & 720 \\
\hline Mata & 170 & 170 & 660 \\
\hline Pastagem & 360 & 140 & 500 \\
\hline \multirow[t]{2}{*}{ Pinus } & 240 & 80 & 680 \\
\hline & \multicolumn{3}{|c|}{$10-20 \mathrm{~cm}$} \\
\hline Eucalipto & 150 & 130 & 720 \\
\hline Mata & 140 & 160 & 700 \\
\hline Pastagem & 300 & 150 & 550 \\
\hline \multirow[t]{2}{*}{ Pinus } & 220 & 90 & 690 \\
\hline & \multicolumn{3}{|c|}{$20-40 \mathrm{~cm}$} \\
\hline Eucalipto & 170 & 130 & 700 \\
\hline Mata & 130 & 170 & 700 \\
\hline Pastagem & 310 & 80 & 610 \\
\hline Pinus & 250 & 130 & 620 \\
\hline
\end{tabular}

Quadro 2. Características químicas das quatro amostras de Latossolo estudadas, sob condições naturais (antes da aplicação dos tratamentos), para três profundidades de coleta do solo

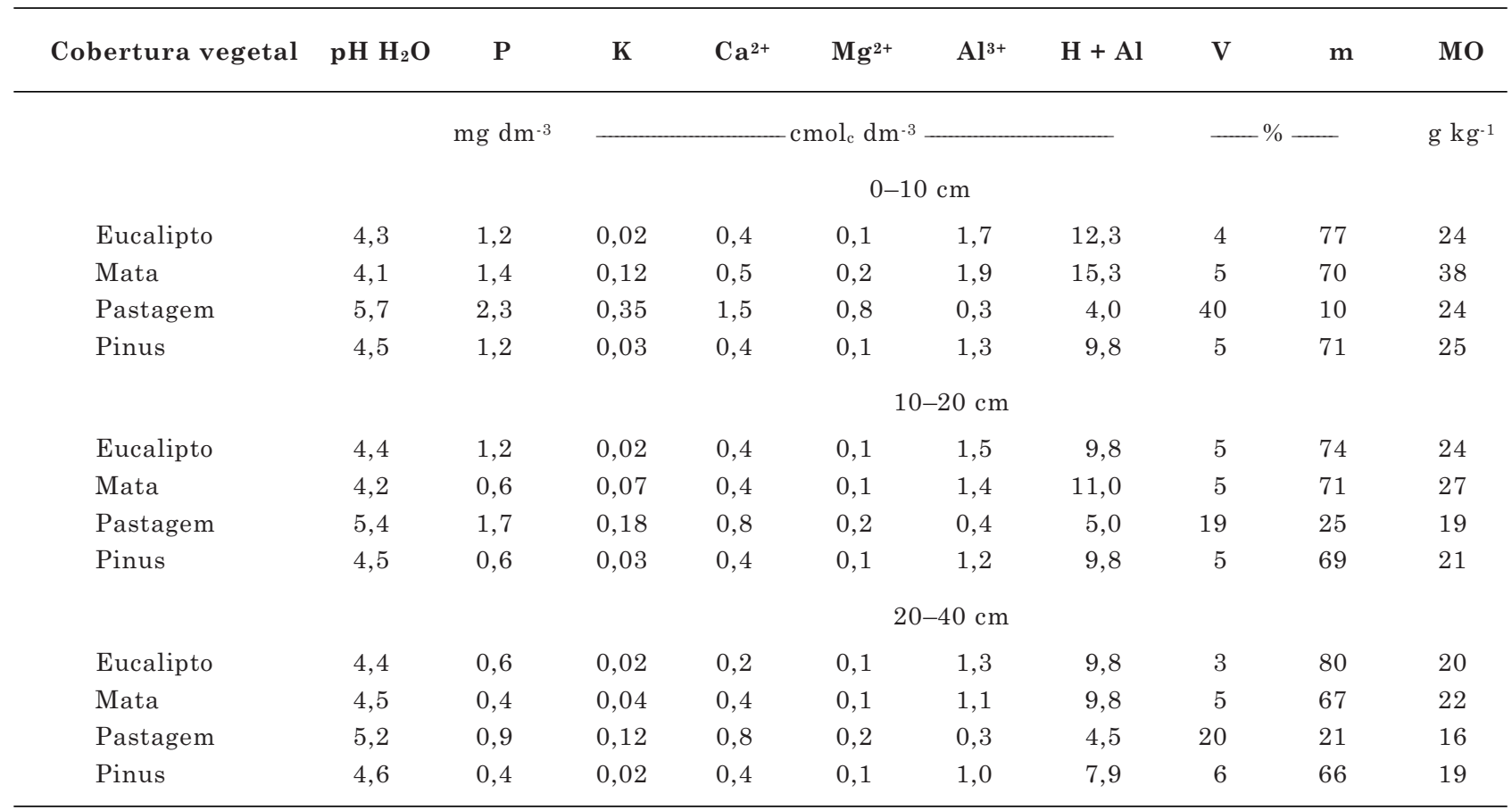

MO, matéria orgânica; V, saturação por bases; m, saturação por Al. 
decumbens L.; a floresta de pinus foi implantada há cerca de 20 anos, o mesmo ocorrendo na área sob floresta de eucalipto.

O experimento foi realizado em colunas de PVC de $10 \mathrm{~cm}$ de diâmetro e $40 \mathrm{~cm}$ de altura, as quais foram preenchidas com amostras deformadas de solo das quatro áreas sob diferentes coberturas vegetais. Antes de serem empacotadas nas colunas de PVC, as amostras de solo foram secas, destorroadas, peneiradas (peneira de malha de $2 \mathrm{~mm}$ ) e, após a aplicação dos tratamentos, dispostas em colunas, para o cultivo subseqüente do algodoeiro, nas mesmas profundidades coletadas em campo. A densidade do solo, considerando as amostras já dispostas na coluna de PVC, variou de 1,0 a $1,15 \mathrm{~g} \mathrm{~cm}^{-3}$. A capacidade de retenção de água das amostras de solos empacotadas nas colunas experimentais, considerando a capacidade de campo e a pressão de $6 \mathrm{KPa}$, variou de 0,30 a $0,37 \mathrm{~cm}^{3} \mathrm{~cm}^{-3}$ de solo.

Os tratamentos consistiram da combinação de sistemas de manejo da calagem com as coberturas vegetais anteriores do Latossolo estudado. Em relação ao manejo da calagem, foram avaliados os seguintes tratamentos: (1) testemunha - sem calagem (SC); (2) calcário aplicado em superfície (CS); (3) calcário incorporado na camada de solo de $0-10 \mathrm{~cm}$ (C10) e (4) calcário incorporado na camada de solo de $0-20 \mathrm{~cm}$ (C20); Esses tratamentos foram combinados com quatro coberturas vegetais anteriores do solo em estudo: sob mata, sob floresta de pinus, sob floresta de eucalipto e sob área de pastagem de braquiária, perfazendo, assim, um total de 16 tratamentos (quatro métodos de manejo da calagem versus quatro coberturas vegetais do Latossolo).

Antes do plantio do algodoeiro, foi efetuada a calagem nos sistemas de manejo já descritos, sendo as amostras incubadas, por 30 dias, com o teor de água do solo mantido na capacidade de campo. Foi utilizado, o $\mathrm{CaCO}_{3}$ p.a. (PRNT igual a $100 \%$ ) com o objetivo de elevar a saturação por bases a $80 \%$, exceto para a testemunha, em que não foi feita a calagem. Optouse pela $\mathrm{V}$ igual a $80 \%$, considerando o estudo de calibração anterior que revelou a necessidade de ser a calagem calculada, com vistas em atingir esse valor teórico, para que, de fato, seja atingido, em condições de estudos de casa de vegetação, o nível de saturação por bases ideal para o algodoeiro, no caso $70 \%$, conforme a tabela de adubação do estado de São Paulo. A quantidade de calcário, para cada tratamento, foi calculada pelo método do IAC, que se baseia na elevação da saturação por bases a um valor ideal para a cultura a ser instalada. O calcário foi aplicado em uma única vez, para os diferentes tratamentos estudados, sendo adicionada, nas diferentes profundidades de incorporação de corretivo, a dose total calculada para a camada de solo de $0-20 \mathrm{~cm}$. No solo sob mata, foram aplicados 2,72 $\mathrm{g} \mathrm{kg}^{-1}$ de $\mathrm{CaCO}_{3}$ p.a.; no solo sob eucalipto, 2,28 $\mathrm{g} \mathrm{kg}^{-1}$; na área de pinus, $2,02 \mathrm{~g} \mathrm{~kg}^{-1} \mathrm{e}$, no solo sob pastagem, $0,84 \mathrm{~g} \mathrm{~kg}^{-1}$. Nas parcelas experimentais e na testemunha (ausência de calagem), aplicou-se $0,64 \mathrm{~g} \mathrm{~kg}^{-1}$ de fosfato de Ca p.a. $\left[\mathrm{Ca}\left(\mathrm{H}_{2} \mathrm{PO}_{4}\right)_{2}\right.$ $\mathrm{H}_{2} \mathrm{O}$ em cada vaso de cultivo, para atender à exigência nutricional do algodoeiro em fósforo.

A correção do solo com micronutrientes foi feita utilizando-se $\mathrm{H}_{3} \mathrm{BO}_{3}\left(0,52 \mathrm{mg} \mathrm{kg}^{-1}\right), \mathrm{ZnSO}_{4} \cdot 7 \mathrm{H}_{2} \mathrm{O}$ $\left(5,27 \mathrm{mg} \mathrm{kg}^{-1}\right)$ e $\mathrm{CuSO}_{4}\left(1,57 \mathrm{mg} \mathrm{kg}^{-1}\right)$, em aplicação única na etapa de plantio do algodoeiro. Durante a fase de incubação do solo com corretivo, o teor de água no solo foi mantido por meio de pesagens diárias dos vasos de cultivo $(3,14 \mathrm{~L})$, mantendo-se a umidade do solo na capacidade de campo. Diariamente, a suplementação de água ao solo era feita de modo lento e gradual, de acordo com a capacidade de infiltração do solo, sem que ocorresse excesso de água na superfície e sem que houvesse escorrimento de água pelas bordas das colunas.

Amostras de solo foram coletadas para efetuar as determinações laboratoriais após 30 dias de reação do calcário. As amostras de solo do tratamento referente à cobertura vegetal anterior de pinus, no tratamento com calagem em superfície (CS), foram perdidas no início do experimento (após 30 dias de incubação do solo para reação do calcário), sendo esta a explicação pela ausência de dados em gráficos do tratamento Pinus/CS. Em relação aos atributos avaliados, foram analisados os teores trocáveis de $\mathrm{Ca}$ e $\mathrm{Al}$, o pH em água, bem como quantificados os valores de saturação por bases $(\mathrm{V})$, para as seguintes camadas de solo: $0-5$, 5-10, 10-20 e 20-40 cm. Utilizou-se a solução de KCl $1 \mathrm{~mol} \mathrm{~L}^{-1}$ para extrair $\mathrm{Ca}^{2+} \mathrm{e} \mathrm{Al}^{3+}$. A acidez potencial foi estimada por meio da medição do $\mathrm{pH}$ em soluçãotampão SMP. A matéria orgânica foi determinada pelo método colorimétrico, a partir de uma solução com $\mathrm{Na}_{2} \mathrm{Cr}_{2} \mathrm{O}_{7}$ e $\mathrm{H}_{2} \mathrm{SO}_{4}$ p.a. As marchas analíticas utilizadas neste estudo estão descritas em Silva (1999).

Os procedimentos estatísticos constaram da análise de variância, aplicando-se o teste $\mathrm{F}$ para determinar o grau de significância $(p<0,05)$ dos tratamentos avaliados. Consistiram em fatores de análise os diferentes tratamentos (sem calagem, calagem $0-10 \mathrm{~cm}$, calagem $0-20 \mathrm{~cm}$ e calagem superficial), sendo avaliados também a interação entre os sistemas de incorporação do calcário e os usos anteriores do Latossolo (eucalipto, mata, pastagem e pinus), para as diferentes características químicas do solo avaliadas. Nas interações significativas pelo teste $\mathrm{F}$, foram comparadas as médias de cada tratamento pelo teste de Tukey $(\mathrm{p}<0,05)$.

\section{RESULTADOS E DISCUSSÃO}

\section{pH}

Os dados referentes ao $\mathrm{pH}$ em água, após 30 dias de reação do calcário no solo, encontram-se na figura 1. Nas amostras de solo em que foi realizada a correção da acidez e o calcário foi incorporado a $20 \mathrm{~cm}$, o pH 
esteve próximo da faixa de valores ( $\mathrm{pH}$ em água na faixa de 6,0-6,2) recomendados para o algodoeiro. Entretanto, a incorporação de calcário a $10 \mathrm{~cm}$ de profundidade elevou os valores para além dessa faixa, e, em superfície, acarretou, na camada de solo de 0$5 \mathrm{~cm}$, forte acréscimo nos valores de $\mathrm{pH}$, para níveis próximos da neutralidade. Esses resultados causam preocupação, uma vez que esse excesso na correção da acidez poderá representar menor disponibilidade de nutrientes para as plantas, notadamente de micronutrientes catiônicos, reduzindo a sua absorção pelas plantas, o que representaria uma séria restrição para o crescimento do algodoeiro. À exceção das amostras de solo sob uso anterior de pastagem, os valores de $\mathrm{pH}$ na testemunha (sem calagem) foram muito baixos, o que caracteriza elevada acidez do solo. Sob essas condições de cultivo, pode-se adiantar que o crescimento do algodoeiro será seriamente afetado, por se tratar de cultura pouco tolerante a solos ácidos (Cia et al., 1999).

Nas amostras de solo onde o corretivo foi aplicado em superfície ou incorporado a 0-10 cm, os aumentos de $\mathrm{pH}$, além do local de aplicação do calcário, foram reduzidos, insuficientes para atingir os níveis considerados adequados para cultivo do algodoeiro. A exceção coube ao solo sob uso anterior de pastagem, onde o aumento de $\mathrm{pH}$ foi expressivo, principalmente no tratamento onde o corretivo não foi incorporado (Figura 1). Esses aumentos de pH, em camadas de solos subseqüentes aos locais de adição do corretivo, já foram verificados em outros estudos, sendo exemplo a elevação de $\mathrm{pH}$ em áreas sob SPD (Caires et al., 1998, Pöttker \& Ben, 1998), visto que, nesses estudos, a calagem superficial elevou o $\mathrm{pH}$ do solo até à profundidade de $10 \mathrm{~cm}$. No estudo de Moreira et al. (2001), foi observado um aumento do pH até $10 \mathrm{~cm}$ de profundidade, quando o calcário foi aplicado superficialmente, em comparação à sua incorporação, o mesmo foi observado por Petrere \& Anghinoni (2001), que encontraram valores elevados para $\mathrm{pH}$ nesta profundidade em áreas sob $\mathrm{SPD}$, com o pH do solo alcançando valores inadequados para o desenvolvimento das plantas.

Na camada de solo de 10-20 cm, nas amostras sob uso anterior de mata e com calagem em superfície, foi verificada maior correção da acidez do que nas amostras sob uso de pinus e eucalipto e, comparando os manejos de calagem, verificou-se que a aplicação superficial de calcário em amostras sob uso anterior de mata mostrou-se mais eficiente em elevar o $\mathrm{pH}$ do que quando o corretivo foi incorporado a $10 \mathrm{~cm}$ de profundidade. Isso pode ser comprovado pelo aumento
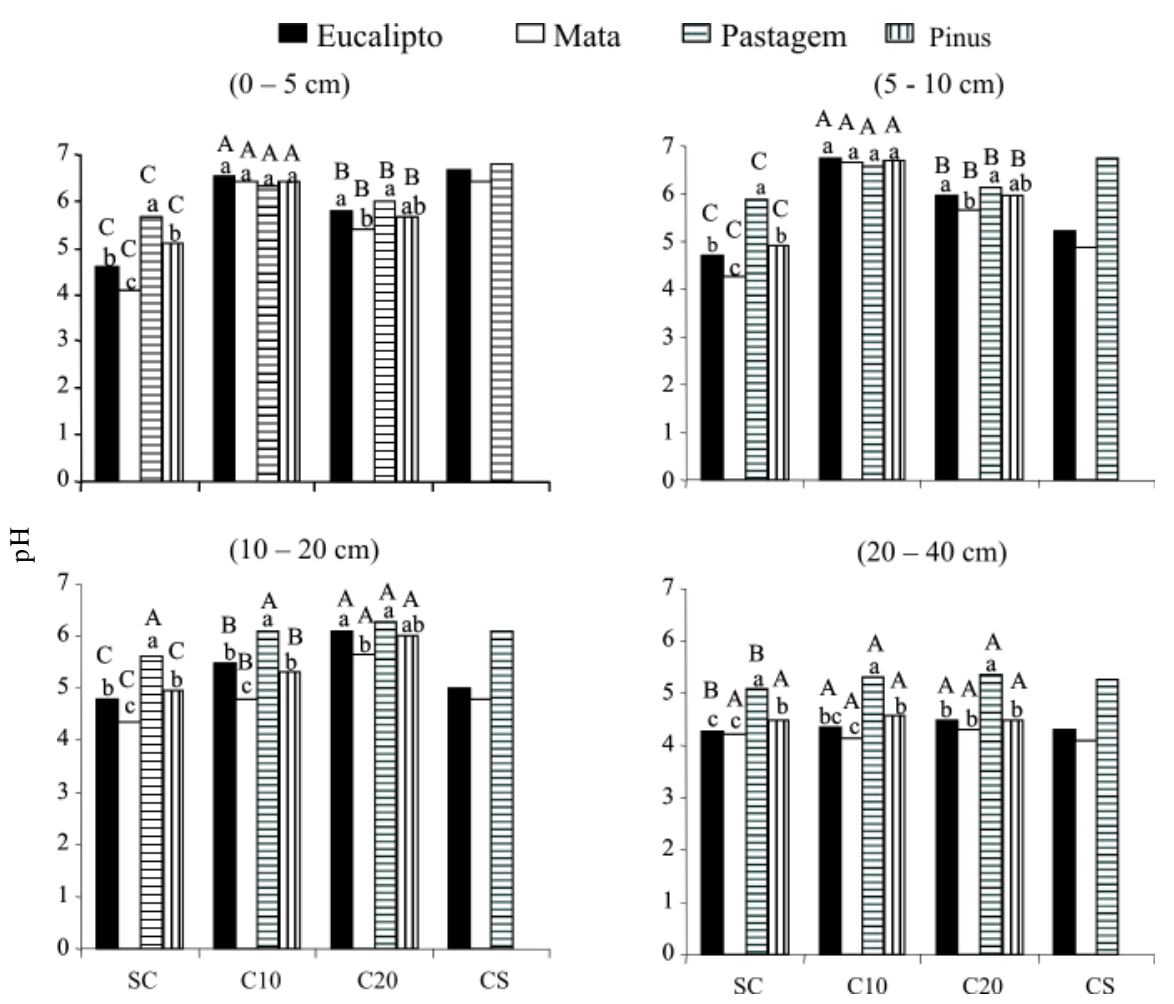

Figura 1. Valores de pH em água de amostras de quatro camadas de Latossolo sob diferentes manejos da calagem e coberturas vegetais anteriores, após 30 dias de incubação do calcário. Médias seguidas de mesma letra minúscula, dentro de cada manejo da calagem, e de maiúscula, dentro de cada cobertura vegetal, não diferem entre si pelo teste de Tukey $(\mathrm{p}<0,05)$. SC - sem calagem; C10 - calagem incorporada a $10 \mathrm{~cm}$; C20 - calagem incorporada a $20 \mathrm{~cm}$; CS - calagem em superfície. 
do $\mathrm{pH}$ em 0,5 unidade em relação ao valor encontrado para a área sem calagem (Figura 1). Isso pode estar relacionado com o maior teor de matéria orgânica na camada superficial do solo sob mata, com a maior concentração de calcário aplicada na camada de solo de $0-10 \mathrm{~cm}$, o que levaria a um aumento da mobilidade para camadas inferiores do solo de produtos da dissolução do calcário e de ácidos orgânicos complexados, que passariam a exercer influência sobre o ambiente químico dessa profundidade de solo, elevando o $\mathrm{pH}$.

Os trabalhos de Caires et al. $(1999,2002)$ e de Gatiboni et al. (2003) demonstraram que a elevação do $\mathrm{pH}$ em profundidade, pela aplicação superficial de calcário, ocorreu até $60 \mathrm{~cm}$ de profundidade. No trabalho de Chaves et al. (1984), realizado em lavoura cafeeira, verificou-se que o aumento de $\mathrm{pH}$ do solo, pela adição de calcário dolomítico em superfície, restringiu-se às camadas de solo com até $30 \mathrm{~cm}$ de profundidade.

Uma possível explicação para elevação do $\mathrm{pH}$ em maiores profundidades, em razão da aplicação superficial de calcário, baseia-se nas explicações de Petrere \& Anghinoni (2001) e Miyazawa et al. (2000), segundo os quais essa mudança no $\mathrm{pH}$ estaria associada à maior produção de compostos orgânicos hidrossolúveis originados da decomposição de resíduos vegetais no solo. $\mathrm{Na}$ área sob uso anterior de mata, verificou-se um maior teor de matéria orgânica no solo (Quadro 1), e, com a maior presença desses compostos no solo, é bastante provável que haja uma maior mobilidade de Ca no solo, pela reação desse cátion com a MO, formando complexos organometálicos, que poderiam ser originados também a partir da reação com outros cátions de reação ácida $\left(\mathrm{Fe}^{2+}, \mathrm{Mn}^{2+} \mathrm{e} \mathrm{Al}^{3+}\right)$ na solução do solo, o que resultaria na liberação de ânions $\left(\mathrm{OH}^{-}, \mathrm{HCO}_{3}^{-}\right)$, que neutralizariam o $\mathrm{Al}$, provocando a elevação do $\mathrm{pH}$.

\section{Ca e saturação por bases}

Os teores de $\mathrm{Ca}^{2+}$, considerando a combinação dos métodos de manejo da calagem com o uso ou cobertura vegetal do solo, são apresentados na figura $2 . \mathrm{Na}$ área sem calagem, os teores de $\mathrm{Ca}^{2+}$ podem ser classificados como pertencendo às classes de fertilidade baixa ou média, segundo a CFSEMG (1999), portanto insuficientes para o pleno crescimento do algodoeiro, que é bastante exigente nesse nutriente.

Com a correção da acidez do solo, houve um acréscimo nos teores de $\mathrm{Ca}^{2+}$, para valores excessivos, em alguns casos, principalmente na área com calagem em superfície (Figura 2). Esse excesso de Ca em solo pode comprometer a absorção de outros nutrientes pelo algodoeiro, sendo exemplos o Mg e o K, que são cátions que competem com o $\mathrm{Ca}^{2+}$ durante a absorção (Marschner, 1995). Se esses nutrientes não forem supridos de modo balanceado, há sério risco de o algodoeiro não atingir a sua exigência nutricional em relação ao $\mathrm{K}$ e $\mathrm{Mg}$, principalmente. Os dados apresentados permitem inferir que houve movimentação de Ca além da camada de solo onde o corretivo de acidez foi aplicado (Figura 2). Isso pode ser notado no tratamento $\mathrm{C} 10$, onde os teores de $\mathrm{Ca}$ na camada de solo de 10-20 $\mathrm{cm}$ foram maiores em todos os sistemas de cobertura vegetal do solo, em relação à área sem correção da acidez. Esses resultados foram comprovados pela mobilização de $\mathrm{Ca}^{2+}$ no perfil do solo verificados por Chaves et al. (1984); Caires et al. (1999), (2002); Petrere \& Anghinoni (2001); Pöttker \& Ben (1998), que observaram elevação nos teores desse nutriente na camada de solo com profundidade variando de 10 a $60 \mathrm{~cm}$.

Quando a calagem foi realizada em superfície (CS), foram notados aumentos nos teores de Ca trocável, em relação à testemunha, na amostra sob uso anterior de mata e pastagem (Figura 2). Uma possível explicação para esta elevação nos teores de Ca trocável no solo sob cobertura vegetal anterior de mata seria decorrente da maior mineralização da matéria orgânica, o que poderia resultar em maior teor no solo de $\mathrm{NO}_{3}{ }^{-}$, que atuaria como íon acompanhante para o Ca oriundo do calcário.

$\mathrm{Na}$ área sob mata e na camada de solo de 5 a $10 \mathrm{~cm}$, os teores de $\mathrm{Ca}^{2+}$ ficaram dentro da faixa ótima para o cultivo do algodoeiro, segundo CFSEMG (1999). Tratase da área (mata) com as amostras de solo mais ricas em matéria orgânica, o que poderia explicar a maior movimentação para camadas mais profundas do solo do Ca aplicado em superfície (Franchini et al., 1999b). Assim, é possível que o uso de calcário em superfície, aliado à maior aplicação de resíduos, ou à maior disponibilidade de matéria orgânica no solo, acarrete o enriquecimento de Ca ao longo do perfil do solo. Não se pode descartar, contudo, o transporte de partículas finas de calcário aplicado na superfície até à profundidade de $20 \mathrm{~cm}$ pela água percolada no perfil do solo, conforme foi verificado no estudo de Amaral et al. (2004). Do mesmo modo, pode ter havido um fluxo preferencial de água e calcário pelas laterais das colunas de PVC, por não terem sido as bordas dessas colunas vedadas com silicone.

Segundo Franchini et al. (1999b), alguns compostos orgânicos, como citrato e succinato, provenientes de resíduos de espécies vegetais e, ou, componentes da matéria orgânica do solo que podem se ligar ao Ca, contribuem para aumentar o transporte desse cátion para as camadas de subsolo. Essa complexação do Ca com compostos orgânicos aumenta, assim, a eficiência da calagem em superfície, por favorecer a mobilidade de $\mathrm{Ca}^{2+}$ até às camadas de subsuperfície, conforme observado por Cassiolato et al. (2000) e Gatiboni et al. (2003). $\mathrm{O} \mathrm{Ca}^{2+}$, associado a compostos orgânicos, tem a sua carga alterada ao formar complexos do tipo ML, $\mathrm{ML}^{0}$ e $\mathrm{ML}^{+}$(em que $\mathrm{M}=\mathrm{Ca}$ ), favorecendo a sua lixiviação, por alterar sua afinidade com os colóides do solo (Miyazawa et al., 1996). Entretanto, a mobilização de Ca no solo sob cobertura de pastagem, a partir de $20 \mathrm{~cm}$ de profundidade, principalmente nos tratamentos C10 e C20, poderá também estar 

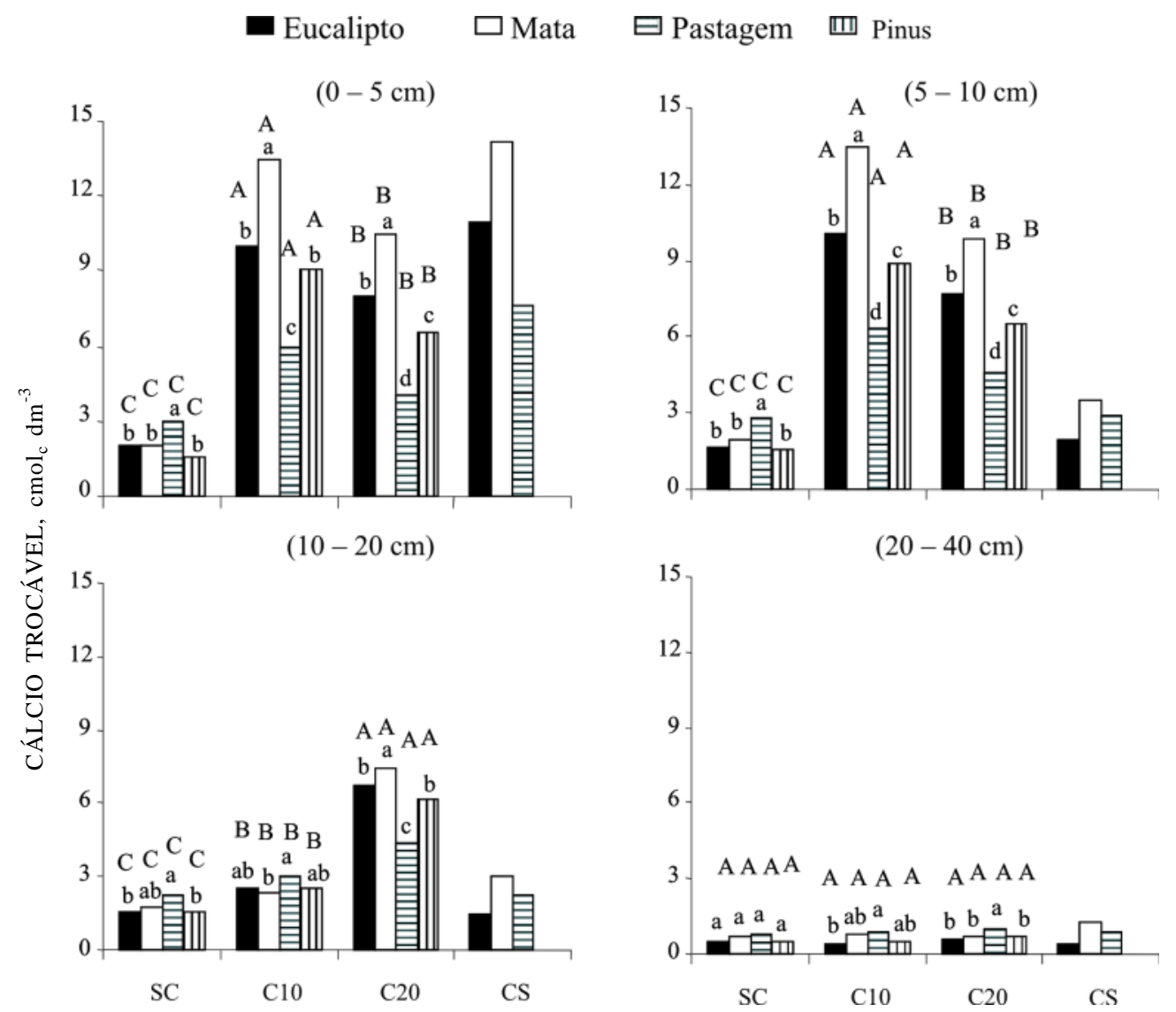

Figura 2. Teores de Ca trocável de amostras de quatro camadas de Latossolo sob diferentes manejos da calagem e quatro coberturas vegetais anteriores, após 30 dias de incubação com calcário. Médias seguidas da mesma letra minúscula, dentro de cada manejo da calagem, e de maiúscula, dentro de cada cobertura vegetal, não diferem entre si pelo teste de Tukey $(p<0,05)$. SC - sem calagem; C10 - calagem a $10 \mathrm{~cm}$; $\mathrm{C} 20$ - calagem a $20 \mathrm{~cm}$; CS - calagem em superfície.

relacionada com a presença de ânions $\left(\mathrm{NO}_{3}{ }^{-}, \mathrm{SO}_{4}{ }^{2-}, \mathrm{Cl}^{-}\right.$, etc.) provenientes de fertilizantes e da matéria orgânica do solo (MOS), que estariam presentes nesse solo e que, ao se ligaram ao Ca, favoreceriam a sua lixiviação.

Em relação à baixa mobilidade de corretivo observada nas áreas sob pinus e eucalipto, a explicação poderia estar ligada à reduzida disponibilidade de ânions estáveis no solo, uma vez que, conforme discutido por Meda et al. (2002), a reação do calcário disponibiliza $\mathrm{Ca}^{2+}$ e $\mathrm{HCO}_{3}{ }^{-}$e, posteriormente, $\mathrm{CO}_{2} \mathrm{e}$ $\mathrm{H}_{2} \mathrm{O}$. Assim, a possibilidade de uma baixa quantidade ou inexistência de ânions inorgânicos no solo e a ausência de ânions orgânicos provenientes de resíduos vegetais dessas coberturas capazes de se ligarem ao Ca poderiam limitar a movimentação do nutriente no solo. Além disso, nesses solos, a disponibilidade de matéria orgânica é menor.

Em relação aos níveis de saturação por bases (Figura 3), os resultados obtidos foram muito similares aos observados para o Ca trocável. Quando o calcário foi incorporado na camada de solo de 0 a $20 \mathrm{~cm}$, os valores de $\mathrm{V}$ estiveram próximos do valor considerado adequado (60\%) para o cultivo do algodoeiro, conforme a CFSEMG (1999). Nas amostras de solo onde o calcário foi incorporado na camada de solo de $0-10 \mathrm{~cm}$, os valores de $\mathrm{V}$ foram mais elevados, superiores, portanto, ao valor considerado adequado para o pleno crescimento do algodoeiro, e isso caracteriza uma supercalagem, com todos os efeitos negativos que se possa antever desse processo sobre a absorção de nutrientes e produção das culturas em geral. Uma calagem excessiva também foi verificada na camada de solo de $0-5 \mathrm{~cm}$ do tratamento CS, uma vez que os valores de $\mathrm{V}$ foram maiores que $70 \%$, nível considerado ótimo para o algodoeiro. Aumentos nos níveis de $\mathrm{V}$ para além do local de aplicação do corretivo ocorreram na camada de $10-20 \mathrm{~cm}$ do tratamento $\mathrm{C} 10$, em todas as coberturas vegetais anteriores do solo. Para as amostras de solo sob cobertura vegetal anterior de mata que receberam calcário em superfície, foi observada também uma elevação nos níveis de saturação por bases ao longo do perfil das amostras de solo (Figura 3). 


$$
\begin{aligned}
& \text { Eucalipto } \square \text { Mata } \quad \boxminus \text { Pastagem } \quad \text { 血 Pinus } \\
& (0-5 \mathrm{~cm})
\end{aligned}
$$

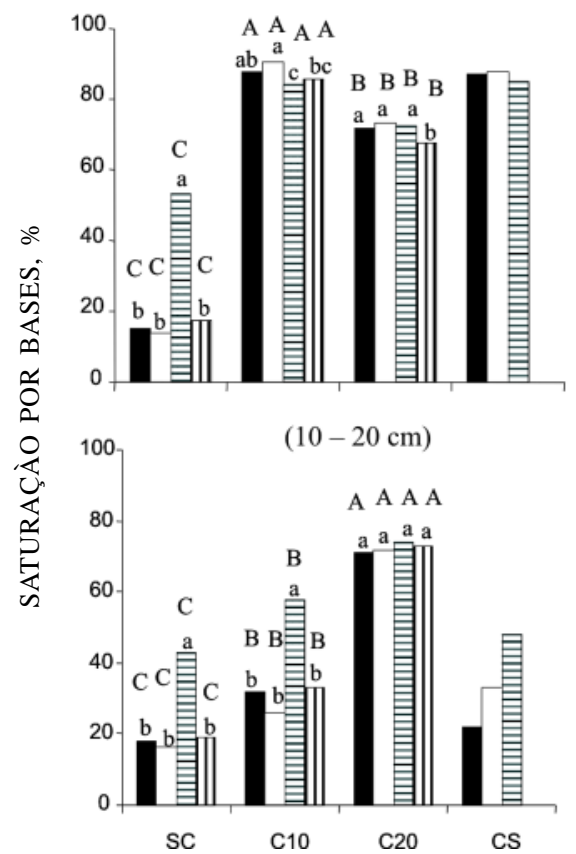

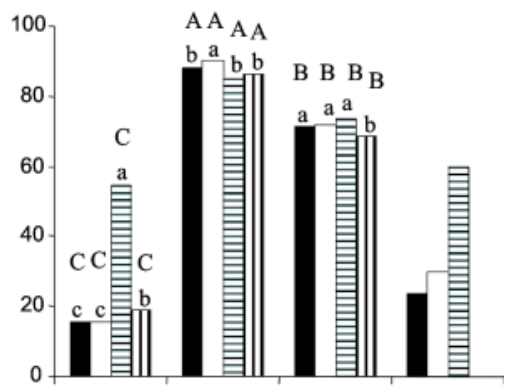

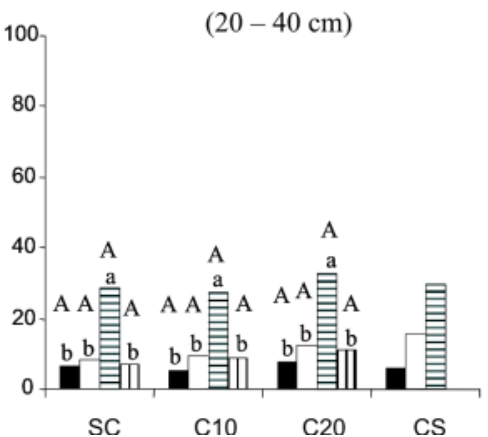

Figura 3. Valores de saturação por bases (V) de amostras de quatro camadas de Latossolo sob diferentes manejos da calagem e coberturas vegetais anteriores, após 30 dias de incubação do calcário. Médias seguidas da mesma letra minúscula, dentro de cada manejo da calagem, e de maiúscula, dentro de cada cobertura vegetal, não diferem entre si pelo teste de Tukey $(p<0,05)$. SC - sem calagem; C10 - calagem a $10 \mathrm{~cm}$; C20 - calagem a $20 \mathrm{~cm}$; CS - calagem em superfície.

\section{Alumínio}

Os teores de $\mathrm{Al}^{3+}$ encontram-se na figura 4. Nas camadas de solo onde houve incorporação de calcário, verificou-se que a neutralização do Al trocável foi plena, o que contribuiu para a melhoria do ambiente radicular. $\mathrm{O}$ mesmo não ocorreu para a testemunha (SC), em que os teores de $\mathrm{Al}$ tóxico foram elevados, o que constitui uma séria restrição ao crescimento das raízes do algodoeiro (Silva et al., 1995). Em geral, os teores de $\mathrm{Al}$ trocável nas amostras com uso anterior de pastagem foram baixos, e isso reflete os valores de $\mathrm{pH}$ em água determinados nessas amostras de solo. No tratamento $\mathrm{C} 10$, houve uma redução nos teores de $\mathrm{Al}^{3+}$ na camada de solo além do local de aplicação do corretivo, em todos os sistemas de uso ou cobertura vegetal do solo, à exceção da área sob uso anterior de pastagem. Essa redução não foi suficiente para caracterizar no solo um ambiente adequado para o crescimento das raízes do algodoeiro, por não ter sido o Al tóxico completamente neutralizado.

No tratamento com CS, a eliminação parcial do $\mathrm{Al}$ tóxico ocorreu ao longo do perfil, exclusivamente nas amostras sob mata, o que poderia ser explicado pela complexação do Al por compostos orgânicos provenientes da matéria orgânica, que está presente em maior quantidade nessas amostras de solo. A complexação do Al por substâncias orgânicas oriundas de resíduos vegetais, como ácido cítrico, oxálico e tartárico, foi descrita e observada por Hue et al. (1986). Esta neutralização do Al ocorreria a partir da lixiviação de complexos organo-metálicos, que alcançariam as camadas subsuperficiais e, então, o Ca deste complexo poderia ser deslocado pelo $\mathrm{Al}$ trocável, pelo fato de esse cátion formar com a MO complexo mais estável do que o Ca (Miyazawa et al., 1996; Franchini et al., 1999a). Assim, o Ca poderia ocupar a carga liberada pelo $\mathrm{Al}$ no complexo de troca, tendo o $\mathrm{Al}$, então, o seu teor trocável reduzido e, posteriormente, mobilizado pelo fluxo de água. Segundo Marschner (1995), a formação de complexos de $\mathrm{Al}$ com compostos orgânicos reduz a atividade desse cátion em solução, em relação à sua presença como íon livre. Provavelmente, isso poderia explicar o maior crescimento das plantas em solos com altos teores de Al tóxico e com maior disponibilidade de matéria orgânica (Hue et al., 1986).

A diminuição no teor de $\mathrm{Al}^{3+}$, para níveis considerados baixos pela CFSEMG (1999), já foi verificada no estudo Pöttker \& Ben (1998), que observaram uma redução nos teores desse cátion até 


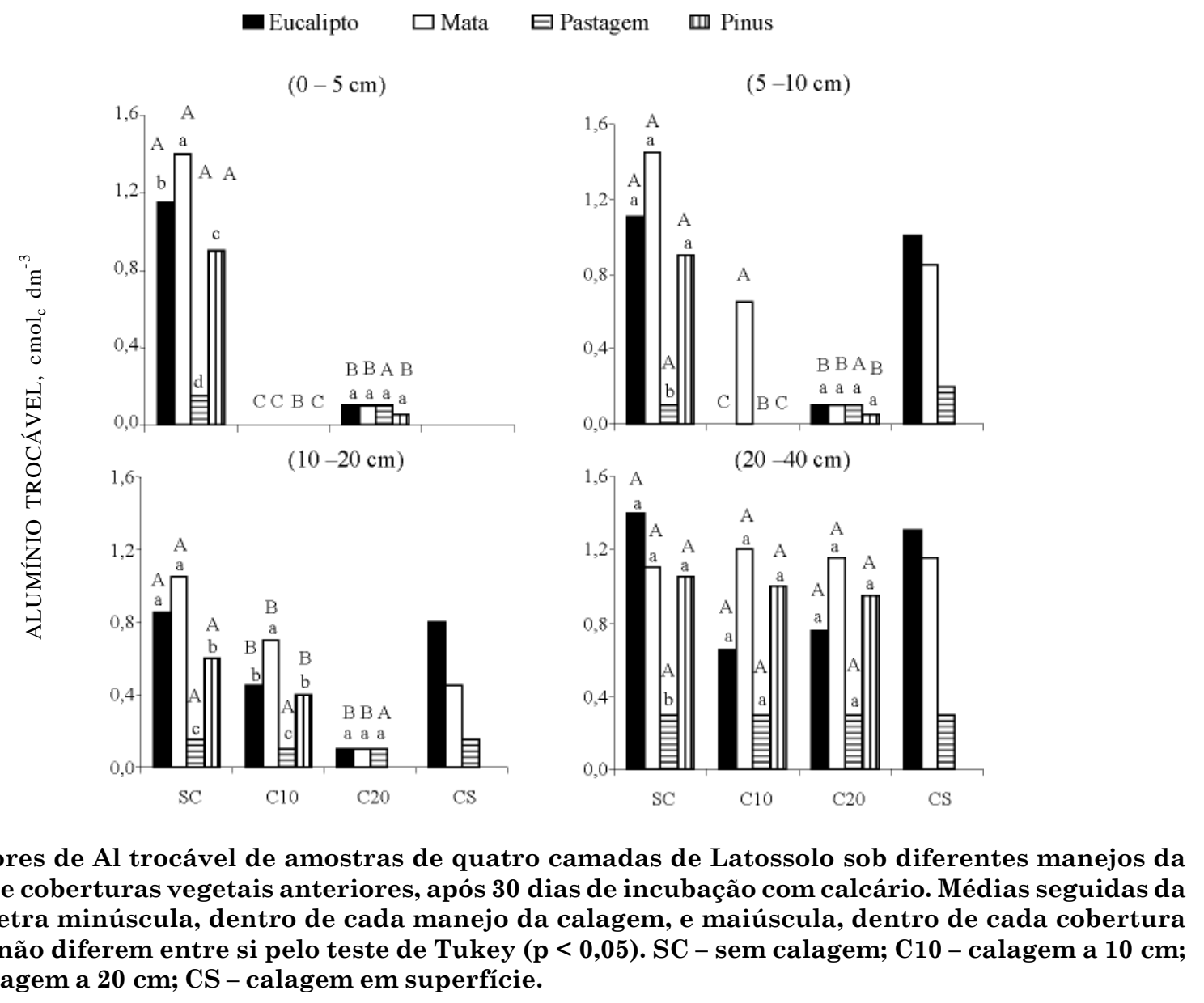

à camada de solo de $10 \mathrm{~cm}$ de profundidade; Petrere \& Anghinoni (2001) observaram uma redução do $\mathrm{Al}^{3+}$ até à profundidade de $20 \mathrm{~cm}$ e Chaves et al. (1984) e Caires et al. (2002) relataram uma redução da atividade do Al para as profundidades de solo de 30 $60 \mathrm{~cm}$. Em ensaios de casa de vegetação, Franchini et al. (2001) observaram que, quando não foram utilizados resíduos de extratos vegetais, a redução no teor de $\mathrm{Al}^{3+}$ pela aplicação superficial do calcário limitou-se aos $5 \mathrm{~cm}$ iniciais de solo; Miyazawa et al. (2002), Franchini et al. (2001) e Cassiolato et al. (2000) observaram que o uso de resíduos vegetais, como a aveia, aveia preta, centeio e nabo forrageiro, proporcionou uma diminuição nos teores de $\mathrm{Al}^{3+}$ até $20 \mathrm{~cm}$ de profundidade, dependendo da espécie vegetal utilizada.

\section{CONCLUSÕES}

1. A aplicação em superfície ou a incorporação de corretivo a $10 \mathrm{~cm}$ de profundidade causaram acréscimos nos valores de $\mathrm{pH}$ e saturação por bases da camada de solo de $0-5 \mathrm{~cm}$ para níveis além dos tecnicamente recomendados para o algodoeiro.

2. Quando o calcário foi incorporado na camada de solo de $0-10 \mathrm{~cm}$, o aumento nos teores de Ca trocável e nos níveis de saturação por bases (V) ocorreu até à profundidade de $20 \mathrm{~cm}$, independentemente da cobertura vegetal anterior. Com a aplicação de calcário em superfície, a maior mobilidade de $\mathrm{Ca}^{2+}$ e o acréscimo na V limitaram-se às áreas com uso anterior do solo com eucalipto, mata e pastagem.

3. Os teores de Al trocável mostraram-se reduzidos em camadas de solo subseqüentes às profundidades de incorporação de corretivo; contudo, a intensidade de redução nos teores de $\mathrm{Al}^{3+}$ não foi suficiente para propiciar condições ótimas de crescimento de raízes, e se mostrou dependente do sistema de manejo da calagem e da cobertura vegetal anterior do Latossolo.

4. Em subsolo (20-40 cm), independentemente dos sistemas de manejo da calagem e de coberturas vegetais avaliadas, não foram alteradas as condições de ambiente para o crescimento de raízes, em relação à área sem calagem. 


\section{LITERATURA CITADA}

AMARAL, A.S.; ANGHINONI, I.; HINRICHS, R. \& BERTOL, I. Movimentação de partículas de calcário no perfil de um Cambissolo em plantio direto. R. Bras. Ci. Solo, 28:359367, 2004.

CAIRES, E.F.; BARTH, G.; GARBUTO, F.J. \& KUSMAN, M.T. Correção da acidez do solo, crescimento radicular $e$ nutrição do milho de acordo com a calagem na superfície em sistema plantio direto. R. Bras. Ci. Solo, 26:1011-1022, 2002.

CAIRES, E.F.; CHUEIRI, W.A.; MADRUGA, E.F. \& FIGUEIREDO, A. Alterações de características químicas do solo e resposta da soja ao calcário e gesso aplicados na superfície em sistema de cultivo sem preparo do solo. $\mathrm{R}$. Bras. Ci. Solo, 22:27-34, 1998.

CAIRES, E.F.; FONSECA, A.F.; MENDES, J.; CHUEIRI, W.A. \& MADRUGA, E.F. Produção de milho, trigo e soja em função das alterações das características químicas do solo pela aplicação de calcário e gesso na superfície, em sistema de plantio direto. R. Bras. Ci. Solo, 23:315-327, 1999.

CASSIOLATO, M.E.; MEDA, A.R.; PAVAN, M.A.; MIYAZAWA, M. \& OLIVEIRA, J.C. Evaluation of oat extracts on the efficiency of lime in soil. Braz. Archive Biol. Technol., 43:533-536, 2000.

CHAVES, J.C.D.; PAVAN, M.A. \& IGUE, K. Resposta do cafeeiro à calagem. Pesq. Agrop. Bras. 19:573-582, 1984

CIA, E.; FREIRE, E.C. \& SANTOS, W.J. Cultura do algodoeiro. Piracicaba, POTAFOS, 1999. 286p.

COMISSÃO DE FERTILIDADE DO SOLO DO ESTADO DE MINAS GERAIS - CFSEMG. RIBEIRO, A.C.; GUIMARÃES, P.T.G. \& ALVAREZ V., V.H. Recomendações para o uso de corretivos e fertilizantes em Minas Gerais. Viçosa, MG, Univerisidade Federal de Viçosa, 1999. 359p.

FRANCHINI, J.C.; MALAVOLTA, E.; MIYAZAWA, M. \& PAVAN, M.A., eds. Alterações químicas em solos ácidos após a aplicação de resíduos vegetais. R. Bras. Ci. Solo, 23:533-542, $1999 \mathrm{~b}$

FRANCHINI, J.C.; MEDA, A.R.; CASSIOLATO, M.E.; MIYAZAWA, M. \& PAVAN, M.A. Potencial de extratos de resíduos vegetais na mobilização do calcário no solo por método biológico. Sci. Agric., 58:357-360, 2001.

FRANCHINI, J.C.; MIYAZAWA, M.; PAVAN, M.A. \& MALAVOLTA, E. Dinâmica de íons em solo ácido lixiviado com extratos de resíduos de adubos verdes e soluções puras de ácidos orgânicos. Pesq. Agropec. Bras., 34:22672276, 1999a.

FRANCHINI, J.C.; MIYAZAWA, M. \& PAVAN, M.A. Influência de resíduos vegetais na toxidez de $\mathrm{Al}$ e na mobilidade de íons no solo. In: FERTBIO 2004, 26., Lages, 2004. Anais. Lages, UDESC, 2004. 1 CD-ROM.

GATIBONI, L.C.; SAGGIN, A.; BRUNETTO, G.; HORN, D. FLORES, J.P.C.; RHEINHEIMER, D.S. \& KAMINSKI, J. Alterações nos atributos químicos de solo arenoso pela calagem superficial no sistema plantio direto consolidado. Ci. Rural, 33:283-290, 2003.

HUE, N.V.; CRADDOCK, G.R. \& ADAMS, F. Effect of organic acids on aluminum toxicity in subsoils. Soil Sci. Soc. Am. J., 50:28-34, 1986.
LIU, J. \& HUE, N.V. Ameliorating subsoil acidity by surface application of calcium fulvates derived from common organic materials. Biol. Fert. Soil, 21:264-270, 1995.

MARSCHNER, H. Mineral nutrition of higher plants. London, Academic Press, 1995. 889 p.

MEDA, A.R.; PAVAN, M.A.; CASSIOLATO, M.E. \& MIYAZAWA, M. Dolomite lime's reaction applied on the surface of a sandy soil of the northwest Paraná, Brazil. Braz. Archive Biol. Technol., 45:219-222, 2002.

MIYAZAWA, M.; PAVAN, M.A. \& CALEGARI, A. Effects of addition crop residues on the leaching of $\mathrm{Ca}$ and $\mathrm{Mg}$ in Oxisols. In: INTERNATIONAL SYMPOSIUM ON PLANT-SOIL INTERACTIONS AT LOW pH, 4., Belo Horizonte, 1996. Resumos. Belo Horizonte, SBCS/ Embrapa-CPAC, 1996. p.8.

MIYAZAWA, M.; PAVAN, M.A. \& FRANCHINI, J.C. Evaluation of plant residues on the mobility of surface applied lime. Braz. Archive Biol. Technol., 45:251-256, 2002.

MIYAZAWA, M.; PAVAN, M.A. \& FRANCHINI, J.C. Neutralização da acidez do perfil do solo por resíduos vegetais. Inf. Agron., 92:1-8, 2000. (Encarte Técnico)

MOREIRA, S.G.; KIEHL, J.C.; PROCHNOW, L.I. \& PAULETTI, V. Calagem em sistema de semeadura direta e efeitos sobre a acidez do solo, disponibilidade de nutrientes e produtividade de milho e soja. R. Bras. Ci. Solo, 25:71-81, 2001.

NOBLE, A.D.; RANDALL, P.J. \& JAMES, T.R. Evaluation of two coal derived organic products in ameliorating surface and subsurface soil acidity. Eur. J. Soil Sci., 46:65-75, 1995.

PETRERE, C. \& ANGHINONI, I. Alteração de atributos químicos no perfil do solo pela calagem superficial em campo nativo. R. Bras. Ci. Solo, 25:885-895, 2001.

PIRES, F.R.; SOUZA, C.M.; QUEIROZ, D.M.; MIRANDA, G.V. \& GALVÃO, J.C.C. Alterações de atributos químicos do solo, estado nutricional e características agronômicas de plantas de milho, considerando as modalidades de calagem em plantio direto. R. Bras. Ci. Solo, 27:121-131, 2003.

PÖTTKER, D. \& BEN, J.R. Calagem para uma rotação de culturas no sistema de plantio direto. R. Bras. Ci. Solo, 22:675-684, 1998.

RHEINHEIMER, D.S.; SANTOS, E.J.S.; KAMINSKI, J. \& XAVIER, F.M. Aplicação superficial de calcário no sistema plantio direto consolidado em solo arenoso. Ci. Rural, 30:263-268, 2000.

SILVA, F.C., org. Manual de análises químicas de solos, plantas e fertilizantes. Brasília, Embrapa Comunicação para Transferência de Tecnologia, 1999. 370p.

SILVA, N.M.; CARVALHO, L.H.; CIA, E.; FUZATTO, M.G.; CHIAVEGATO, E.J. \& ALLEONI, L.R.F. Seja o doutor do seu algodoeiro. Piracicaba, Potafos, 1995. 17p. (Arquivo do Agrônomo, 8)

VALE, F.R.; GUEDES, G.A.A.; GUILHERME, L.R.G. \& FURTINI NETO, A.E. Manejo da Fertilidade do Solo. Lavras, Universidade Federal de Lavras, 1997. 206p. 